\title{
Gender and lung transplantation: Size matters, does sex?
}

\author{
M. Blair Marshall, $M D^{\mathrm{a}}$ \\ Leslie J. Kohman, MD
}

See related editorials on pages 345 and 346.
From the Department of Surgery, University of Pennsylvania School of Medicine, ${ }^{\mathrm{a}}$ Philadelphia, Pa, and the Department of Surgery, Upstate Medical University, ${ }^{\text {b }}$ Syracuse, NY.

Received for publication May 18, 2004; accepted for publication May 24, 2004.

Address for reprints: Margaret Blair Marshall, MD, Department of Surgery, Hospital of the University of Pennsylvania, 3400 Spruce St, 6 Silverstone Pavilion, Philadelphia, PA 19104-4227 (E-mail: Blair. Marshall@uphs.upenn.edu).

J Thorac Cardiovasc Surg 2004;128:352-3 $0022-5223 / \$ 30.00$

Copyright (C) 2004 by The American Association for Thoracic Surgery

doi:10.1016/j.jtcvs.2004.05.014

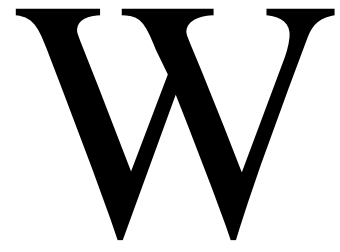

hen evaluating organs for lung-transplant recipients, many issues need to be considered. Donor factors play a key role in the evaluation of organs for transplantation: age, medical history, smoking history, adequate gas exchange, normal bronchoscopy, serologies, ABO compatibilities, and size matching. Donor and recipient gender are neither directly considered nor matched. Should they be? Do the inherent differences between men and women matter in lung transplantation?

There are several reasons to expect a difference when transplanting across organ and recipient gender. Gender-associated differences could play a role in terms of graft survival, organ size, metabolic demands, circulating hormones, and receptors. There are gender-associated immunologic phenomena, such as the female's ability to tolerate certain alloantigens during pregnancy. Does this affect graft survival? Does the fact that women are more susceptible to autoimmune disease play a role in tolerance? For lung transplantation, the data are relatively sparse. However, differences observed in other transplanted organs might give us a clue.

With respect to kidney transplantation, Inoue and colleagues ${ }^{1}$ examined 205 kidney transplantations performed over a 13-year period and found that long-term graft survival was better in female than in male recipients. Cyclosporine (INN: ciclosporin) troughs and steroid dosing tended to be lower among female recipients. When graft survival was analyzed among the 4 possible matched scenarios on the basis of gender, female-to-female transplantation had the best graft survival, whereas male-to-male transplantation had the worst. This issue has been addressed in an animal model of renal allografts in which a protective effect of estradiol was observed on chronic rejections. ${ }^{2,3}$ However, these findings have not been universal.

Multiple studies confirm a worse prognosis for female kidneys transplanted into male recipients when compared with male kidneys transplanted into female recipients. ${ }^{4,5}$ Two hypotheses have been proposed to explain this: the concept of nephron underdosing (ie, the kidney mass is proportionally less in male patients receiving a female kidney) and the hypothesis that there are different immunologic mechanisms playing a role in graft survival. In attempting to evaluate the effect of gender on graft survival and the underlying mechanism, a large study using the database of the Collaborative Transplant Study analyzed graft survival according to donor and recipient gender for renal $(\mathrm{n}=124,911)$, cardiac $(\mathrm{n}=25,432)$, and hepatic $(\mathrm{n}=$ $16,410)$ organs. This study attempted to discern whether the gender effect observed in renal transplantation was related to inherent immunologic mechanisms or nephron underdosing. If the effect was observed in kidneys alone, this would point toward nephron underdosing, whereas an effect across all organs would suggest an immunologic mechanism. Several cofactors were considered, including calendar year, geographic location, race, donor and recipient age, HLA mismatch, and cold ischemic time. Survival of cadaveric renal transplants was consistently lower when the donor was female. From this study, there was a donor gender-associated risk ratio of 1.15 in female recipients and 1.22 in male recipients. The gender effect observed was more pronounced for younger $(<45$ years) compared with older donors ( $>45$ years). This effect was observed even in HLA-identical siblings. Because the observed effect was age associated, the role of hormonal milieu on graft survival is likely to be important. When the authors looked at cardiac transplantations, again there was a gender-associated risk ratio of 1.13 for the graft of female 
donor organs into male recipients. There was no difference in graft survival from male donor organs into either female or male recipients. These observations are similar to those reported in other smaller studies. ${ }^{6,7} \mathrm{~A}$ similar effect has been observed in hepatic transplantation. Kahn and cowork$\mathrm{ers}^{8}$ reported a 3.7-fold higher risk of graft failure in livers from female donors transplanted into male recipients. This has been confirmed in several other series. ${ }^{9,10}$

Data from animal studies suggest immunologic mechanisms might play a role. Female kidneys display more HLA antigens and are more antigenic than their male counterparts. ${ }^{11}$ However, HLA matching does not obliterate the observed gender effects, and therefore other mechanisms could play a role. There might be an effect at the donorrecipient interface, perhaps at the level of the vascular endothelium. Endothelial cells have different responses to androgens and estrogens. ${ }^{12}$ In animal studies of heart allograft transplantation during cyclosporine use, 4 gender combinations were used to examine the effect of donor and recipient gender on graft survival. ${ }^{13}$ In this study graft survival was significantly worse in female recipients, and this effect could be attenuated with tamoxifen.

For lung transplantation, there are relatively fewer procedures performed, and therefore the data are scarce. As of yet, there are no published animal studies that evaluate the effect of gender on pulmonary graft function or survival, although some human data attempt to address this issue. Christie and associates ${ }^{14}$ analyzed organ and recipient gender on the incidence of primary graft failure. Female donor gender was associated with the development of graft failure, with an unadjusted risk ratio of 3.99 (95\% confidence interval $[\mathrm{CI}], 1.74-9.11 ; P=.001)$. This remained significant when adjusted for all other risk factors. Although recipient gender initially appears to have an effect as well, statistical significance was lost when adjusted for donor gender.

In the 19th official registry report of the International Society for Heart and Lung Transplantation, ${ }^{15}$ donor-recipient gender mismatch was a risk factor for 1-year mortality, with an odds ratio of 1.19 (95\% CI, 1.03-1.37; $P=.02)$, and female recipient gender was a risk factor for 5-year mortality, with an odds ratio of 0.74 (95\% CI, 0.61-0.90; $P=$ .002) in transplantations performed between April 1994 and December 1996. However, in the more recent 20th official report, ${ }^{16}$ donor or recipient gender was not identified as a significant risk factor for either 1- or 5-year mortality.

For lung transplantation, the issue of gender and its implications on graft function and long-term survival have not been clearly established. Certainly, the effects of gender and hormones might more easily be isolated and analyzed in an animal model, but the applicability to human subjects will not be known until additional clinical data become available. As we continue to improve on other factors that affect outcome in lung transplantation, gender mismatch needs to be more carefully investigated to determine whether it is truly a risk factor for long-term graft survival.

\section{References}

1. Inoue S, Yamada Y, Kuzuhara K, Ubara Y, Hara S, Ootubo O. Are women privileged organ recipients? Transplant Proc. 2002;34:2775-6.

2. Muller V, Szabo A, Viklicky O, Gaul I, Portl S, Philipp T, et al. Sex hormones and gender-related differences: their influence on chronic renal allograft rejection. Kidney Int. 1999;55:2011-20.

3. Gafter U, Ben-Bassat M, Levi J. Castration inhibits glomerular hypertorphy and proteinuria in uninephrectomized male rats. Eur J Clin Invest. 1990;20:360-5.

4. Neugarten J, Silbiger SR. The impact of gender on renal transplantation. Transplantation. 1994;15:1145-52.

5. Vereerstraeten P, Wissing M, De Pauw L, Abramowicz D, Kinnaert P. Male recipients of kidneys from female donors are at increased risk of graft loss from both rejection and technical failure. Clin Transplant. 1999;13:181-6.

6. Prendergast TW, Furukawa S, Beyer AJ 3rd, Browne BJ, Eisen HJ, Jeevanandam V. The role of gender in heart transplantation. Ann Thorac Surg. 1998;65:88-94.

7. Mehra MR, Stapleton DD, Ventura HO, Escobar A, Cassidy CA, Smart FW, et al. Influence of donor and recipient gender on cardiac allograft vasculopathy. An intravascular ultrasound study. Circulation. 1994;90:1178-82.

8. Kahn D, Gavaler JS, Makowka L, van Thiel DH. Gender of donor influences outcome after orthotopic liver transplantation in adults. Dig Dis Sci. 1993;38:1485-8.

9. Marino IR, Doyle HR, Aldrighetti L, Doria C, McMichael J, Gayowski $\mathrm{T}$, et al. Effect of donor age and sex on the outcome of liver transplantation. Hepatology. 1995;22:1754-62.

10. Brooks BK, Levy MF, Jennings LW, Abbasoglu O, Vodapally M, Goldstein RM, et al. Influence of donor and recipients gender on the outcome of liver transplantation. The possible existence of maternal effect. Transplantation. 1996;27:1784-7.

11. Panajotopoulos N, Ianhez LE, Neumann J, Sabbaga E, Kalil J. Immunologic tolerance in human transplantation. The possible existence of a maternal effect. Transplantation. 1990;50:443-5.

12. McCrohon JA, Jessup W, Handelsman DJ, Celemajer DS. Androgen exposure increases human monocyte adhesion to vascular endothelium and endothelial cell expression of vascular cell adhesion molecule-1. Circulation. 1999;99:2317-22.

13. Zou Y, Steurer W, Klima G, Obrist P, Margreiter R, Brandacher G. Estradiol enhances murine cardiac allograft rejection under cyclosporin and can be antagonized by the antiestrogen tamoxifen. Transplantation. 2002;74:354-7.

14. Christie JD, Kotloff RM, Pochettino A, Arcasoy SM, Rosengard BR, Landis JR, et al. Clinical risk factors for primary graft failure following lung transplantation. Chest. 2003;124:1232-41.

15. Hertz MI, Taylor DO, Trulock EP, Boucek MM, Mohacsi PJ, Edwards LB, et al. The Registry of the International Society for Heart and Lung Transplantation: nineteenth official report-2002. J Heart Lung Transplant. 2002;21:950-70.

16. Trulock EP, Edwards LB, Taylor DO, Boucek MM, Mohacsi PJ, Keck $\mathrm{BM}$, et al. The Registry of the International Society for Heart and Lung Transplantation: twentieth official adult lung and heart transplant report-2003. J Heart Lung Transplant. 2003;22:625-35. 